\title{
Drug Addicts' Behavior and the Built Environment of the Old City of Jerusalem
}

\author{
Leila Bustami ${ }^{*}$, Nisreen Harhash \\ Department of Architecture, University of Petra, Jordan
}

Copyright (C) 2015 by authors, all rights reserved. Authors agree that this article remains permanently open access under the terms of the Creative Commons Attribution License 4.0 International License

\begin{abstract}
This study explores the contribution of the built environment of the old city of Jerusalem to the widespread drug abuse phenomenon there. Using the ethnographic interviewing method, 6 recovered addicts viewed pictures of 16 related locations in the Muslim quarter of the city and recalled how they saw and used them. After qualitative analysis of the collected narratives, it was found that the city's distinguished features (old walls, deteriorating crowded houses, abandoned enclosures, dark angled alleyways, and isolated areas) helped addicts to avoid being arrested or robbed as well as to abuse drug safely. This environment-behavior relationship conforms with Gibson's (1979) ecological psychology of visual perception and recognizes the affordances of those features which through preserving and vitalizing, can be made less attractive to addicts and more life sustaining to all.
\end{abstract}

Keywords Addicts, Built Environmental Features, Drug Abuse Behavior, Old City of Jerusalem

\section{Introduction}

The historic Old City of Jerusalem (OCoJ) in the heart of the Middle East region is witnessing an extensive spread and continuous rise of drug abuse among its Palestinian residents $[1,2]$. Recent statistics show that the number of addicts in Jerusalem and its environs has exceeded 6,000 in addition to 25,000 casual users [3].

Some researchers link this environmental phenomenon to the Israeli occupation of the West Bank and Gaza Strip in 1967. Since then, Palestinians in those territories have experienced stressful living conditions and suffered from their aftereffects which may have compelled them to abuse drugs. Others put the blame on the socio-economic problems common in the area, while a few thinkers refer to the physical environment of the city as a probable contributor to this phenomenon [4]. Based on this last thought, the researchers of the present study became interested in knowing how addicts in the OCoJ related to their environment and how they utilized it to meet their needs and goals for survival.

\subsection{Drug Abuse Behavior}

Typically, drug addicts have three central events in their everyday lives: a) hustling or obtaining money illegally, b) copping or buying drugs, and c) getting off [5]. They abuse drugs by injecting themselves, snoring or smoking them depending on the drug being used. Events, persons, objects as well as drug abuse locations are all determined "in the light of the need for heroin" [6, p. 65] which is the most commonly used drug in OCoJ [4]. Agar [5] classifies events which connect addicts to their environments as either of the wanted type to safely obtain drugs and abuse them, or of the unwanted type to secure themselves from being arrested or having the drugs stolen. However, in the course of the repeated use of drugs in order to maintain basic functioning and avoid withdrawal symptoms, addicts harm themselves and eventually lose their lives.

\subsection{The Built Environment of the Old City of Jerusalem (OCoJ)}

The OCoJ is an ancient walled community of $0.91 \mathrm{~km}^{2}$ area within the Greater City of Jerusalem. During the course of its history dating from more than 4000 years ago, it was built, destroyed, rebuilt, and developed several times. However, the majority of the city's distinguished features and buildings as they are now originated from the Ottoman period $\left(16^{\text {th }}\right.$ century to 1917$)$ during which the city was a quite attractive hub for commercial activities and worldwide visitors [7, 8]). Figure 1 shows the most distinguished features of the city's built environment which are:

A. The city's walls. A key element and a major attraction of the city physical structure. They are $4200 \mathrm{~m}$ long, $2 \mathrm{~m}$ thick in most places, and about 12 $\mathrm{m}$ high on the average. The approximate enclosed rectangle they form is of 11 gates, 4 of which are closed. The main opened gates link the city with the surrounding neighborhoods and are approached through public plazas of many shops, cafes, and restaurants [9] of which many have underground enclosures.

B. The city's urban divisions, neighborhoods, and courtyards. On the basis of cultural and ethnic 
group identities, one principal road intersection unevenly divides the city into 4 quarters: The Muslim, the Christian, the Armenian, and the Jewish. Those divisions have similar forming elements and structured neighborhoods. Each division has its own sacred buildings and sites, and each neighborhood is crowded with a number of residential complexes of which each contains several housing units that are clustered around one courtyard of one entry point. Those courtyards function as community centers of diverse daily activities important to residents. However, many of the existing buildings especially those in the Muslim quarter need preservation and maintenance.

C. The city's roads. Roads are either residential or commercial. The former type is the alley way described as short, narrow, dead-ended, with many angles and steps in most cases, while the latter is relatively straight, long, and open-ended [7]. Some roads have partial coverings of the vaulting type, but all are for pedestrians.

D. The isolated areas near the city's walls. Those areas are distinguishable because of their emptiness and openness which make them totally different from those of the city's interiors. Some trees, open steps, and built-in seats exist there..

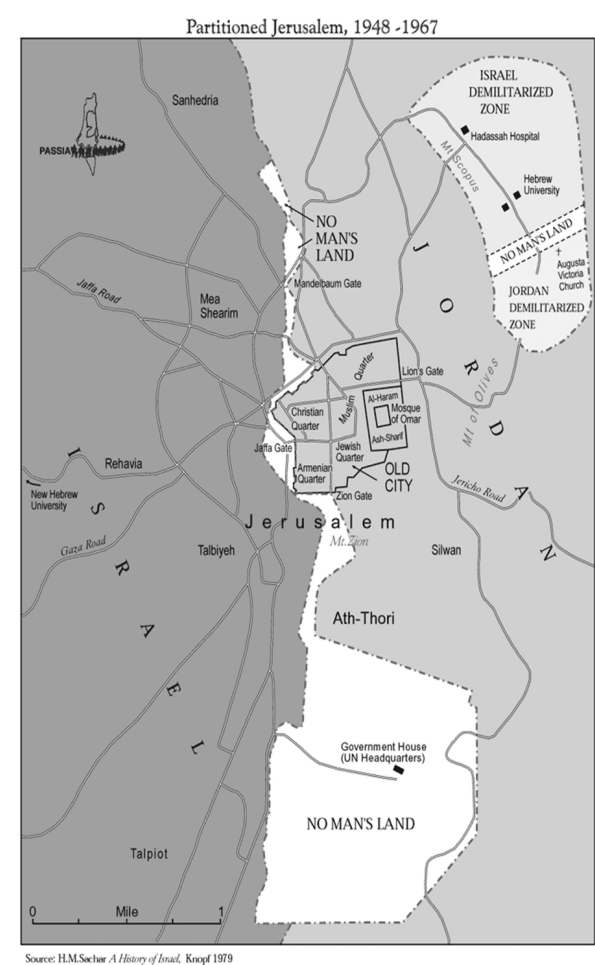

The Old City of Jerusalem as a part of the Greater City of Jerusalem. (Passia, 2006).

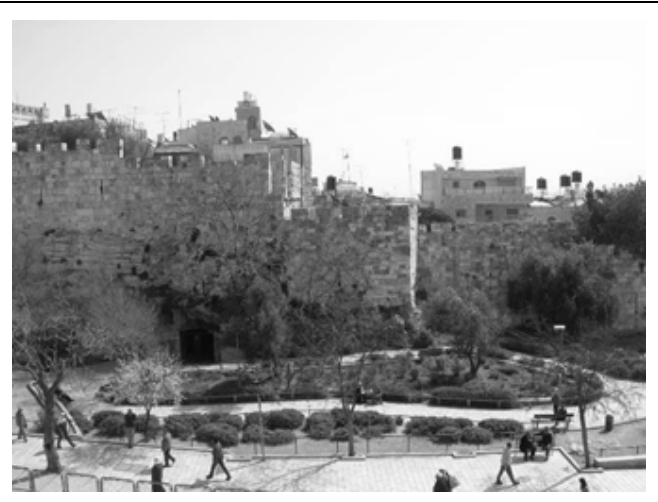

A general view of the Old City of Jerusalem from outside the walls.

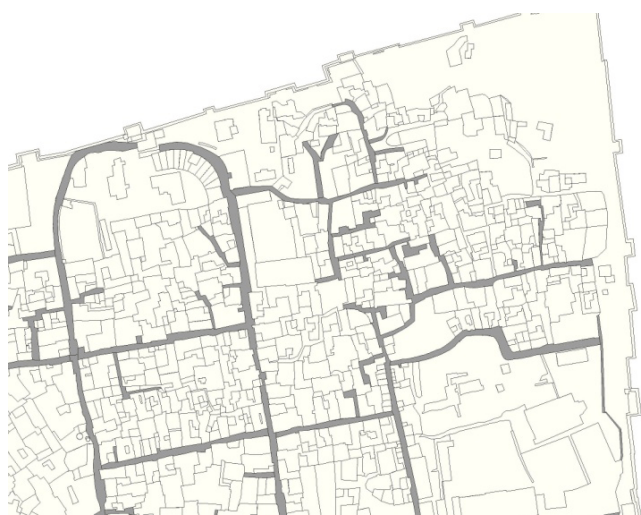

Part of the Muslim quarter showing the morphology of the city. (Welfare association, 2005).

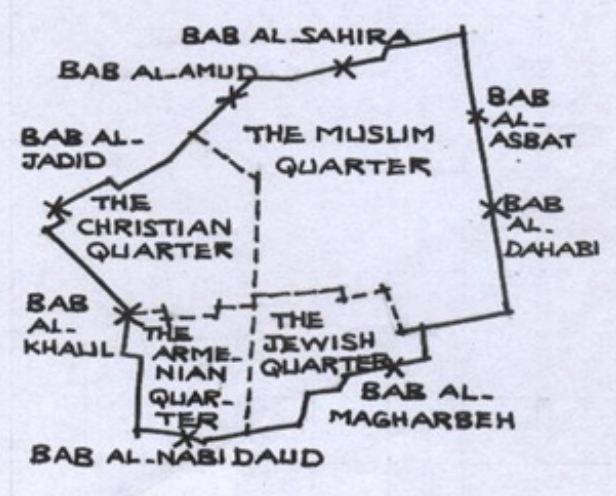

The city's divisions, walls, \& gates (Babs).

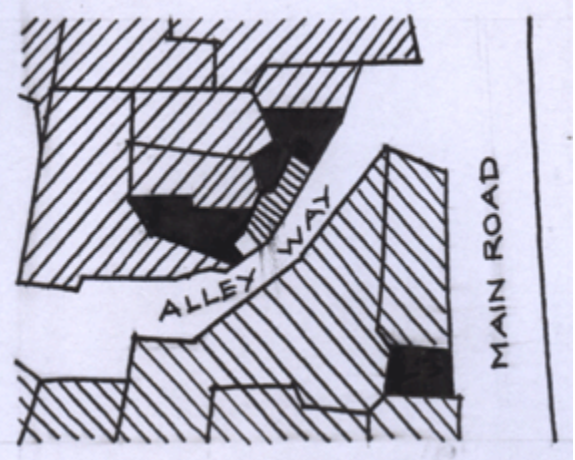

Housing complexes. Hatched areas are the housing units, \& shaded areas are the courtyards.

Figure 1. The distinguished features of the Old City of Jerusalem ( Drawings: The researchers) 
Because of its unique character and historic status, the OCoJ was listed as a "World Heritage" site in 1980, but two years later, it was inscribed as a "Heritage in Danger" due to the neglect and deteriorating state of many of its buildings [8]. In addition, the city suffers from the over-crowdedness of housing units which harms its physical image and causes inadequate levels of natural lighting and ventilation [10] . The city also lacks good public services, playgrounds, and recreational facilities [8]. However, those problems are most obvious in the Muslim quarter which has the highest population rate and the lowest living standards [9, p. 71]. Due to these circumstances and other social problems like poverty and unemployment, some inhabitants abandoned their houses and left the city [11]. But the majority who are attached to their environment or cannot move out are still suffering.

\subsection{Scope, Aim, and Rationale}

The current study is limited to the Muslim quarter of the OCoJ due to practical reasons and because it noticeably exceeds the other three quarters in the wide spread of drugs and the high rate of drug abuse (see Appendix One in Ref.[9], p. 75). The aim was to explore how drug addicts saw and used that environment to meet their needs and goals. Results were expected to raise questions about what to do in order to make addicts change their cognitions and usages of that environment and about the usefulness of approaches such as "Crime Prevention through Environmental Design" [12] for hitting that target, keeping in mind that the wishful change will not to be through reshaping that distinctive environment.

\section{Research Paradigm}

Focusing on drug abuse behavior in the physical environment of the OCoJ suggested an ontology that saw locations related to drug addiction events as meaningful components of addicts' social reality. Evidence of the probable usefulness of those places for drug abuse events went on to encompass an epistemology stating that addicts' situated actions are knowable and can be investigated through observing their sub-cultural settings or through asking addicts themselves. The researchers chose narrative ethnography as the guiding methodological strategy based on Agar's [5, p. 25] view that heroin addicts are a sub-cultural ethnic group. Accordingly, data were expected to take the form of cultural stories capable of reflecting both addicts' situated actions and the supportive role of the features of the related locations.

\subsection{Informants and Photographs}

Three male residents of the $\mathrm{OCoJ}$ and two female social workers from "Al-Sadeq Al-Tayeb" rehabilitation center were selected as informants on the basis of their prior experience, availability, and willingness to help. All were Palestinians who ranged in age from 32 to 49 . With the aid of this voluntary team, the researchers in early June 2005 made 3 walking tours to the Muslim quarter and took 22 colored pictures of places that were most frequently used by drug addicts. These tours, each of which took about three hours, helped facilitate the researchers' awareness about the physical features of the visited places and their properties.

\subsection{Participants}

Following Morse's [13] guidelines for purposive sampling, 6 out of 8 available recovered addicts were selected. They sounded information-rich, cooperative, sincere, realistic, and more clear-minded than real addicts. All were male Palestinians who ranged in age from 43 to 56 and all had had recovered for at least 3 years after a relatively long history with drugs at the Muslim quarter. At the time of conducting the study, all were living in or around OCoJ and employed in local rehabilitation centers. Female participants were not considered as none of them was available.

\subsection{Materials, Methods, and Procedure}

In an interactive session conducted in the "Al-Sadeq Al-Tayeb" center at the end of June 2005, the 6 participants viewed the photographs taken by the researchers, discussed them, and reached a consensus on the ones that depicted places used by most addicts. The session took the form of a group interview and lasted for 2 hours. The chosen pictures, which were 16 in number, were then reported to the researchers who mapped them under coding numbers from 1 to 16 (Figures 2, 3, and 4).

After that, and between July and September 2005, participants were individually interviewed at the "Caritas" rehabilitation center in a meeting room in which the agreed-upon pictures were displayed on a table. Each interviewee viewed the pictures one by one and described his past experience in the simulated places. Each interview took about 1 hour and was tape-recorded. The interview type was the unstructured post modernism in which the researchers' influence was minimal and the how-to rules were forgotten. However, the researchers had to slightly guide the process so as to help the interviewees focus on remembering how they utilized the viewed places. Besides describing actions and events, the collected narratives were able to communicate facts about addicts' cognition of their past experiences. 


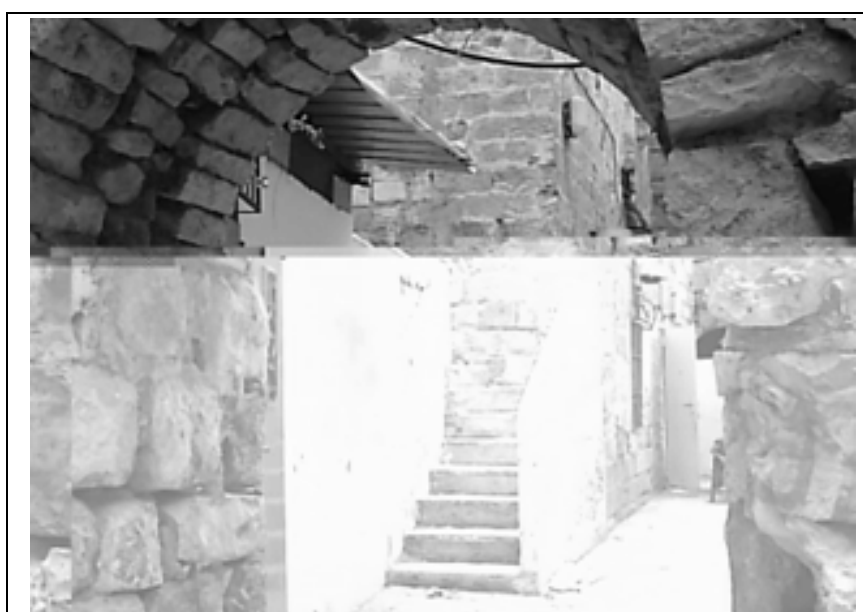

Picture No.1: A typical residential courtyard with a staircase that leads up to the next building's roof.

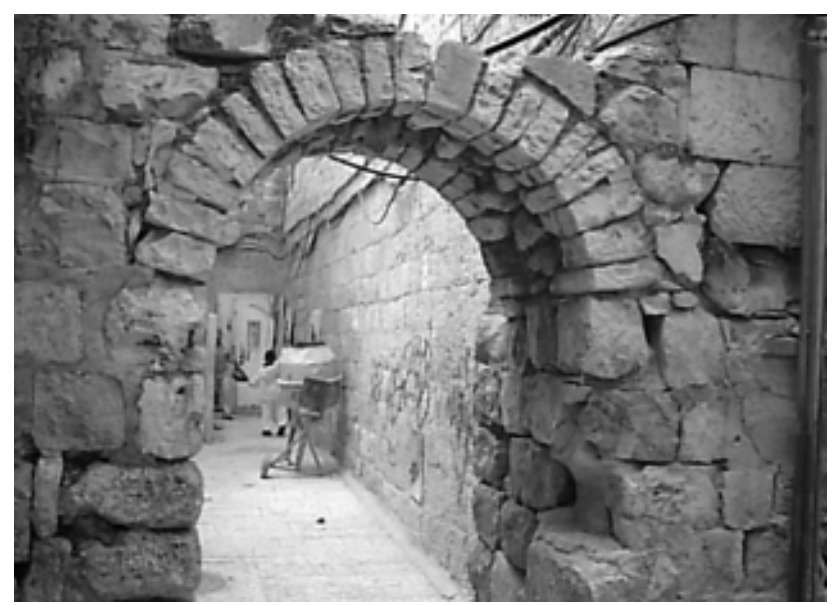

Picture No.2: The entrance of a residential courtyard.

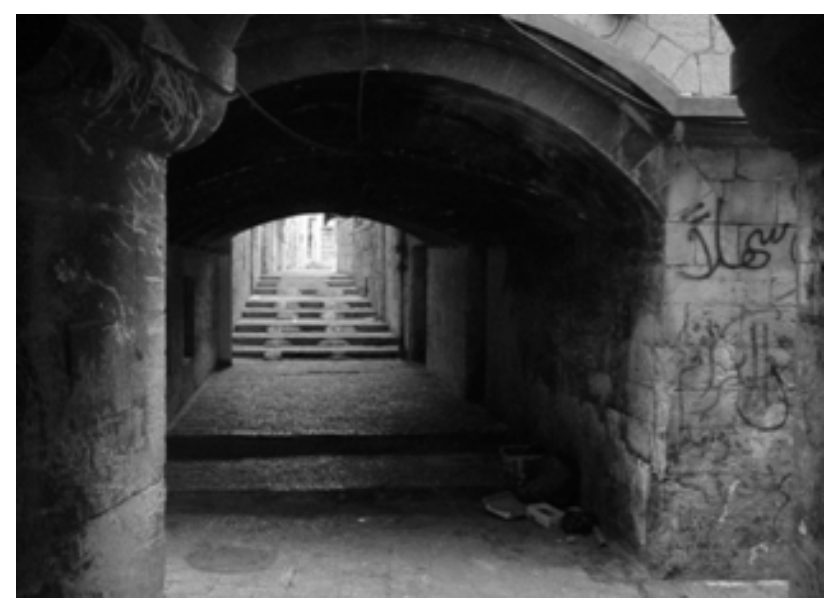

Picture No. 3: A dark alleyway with hidden corners in a residential area.

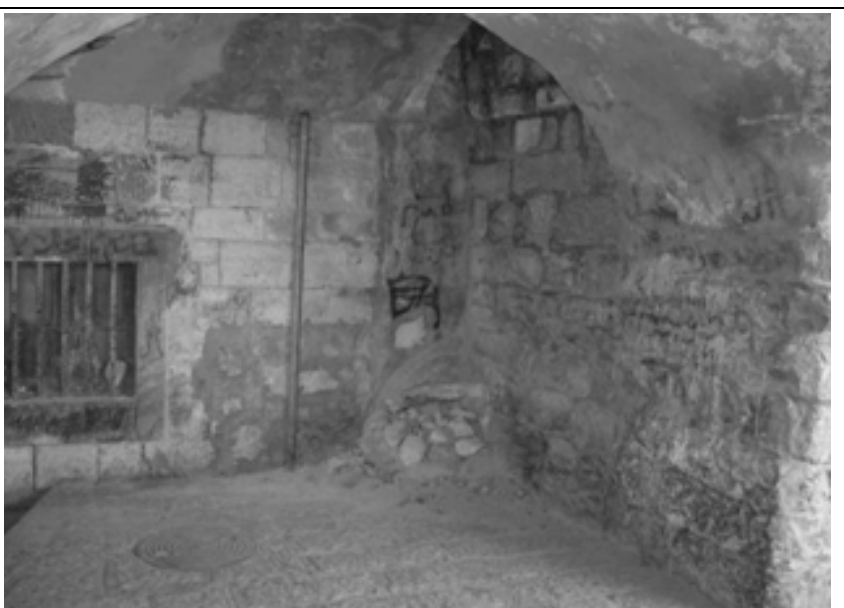

Picture No. 4: A dark deteriorating corner of a dirty residential courtyard.

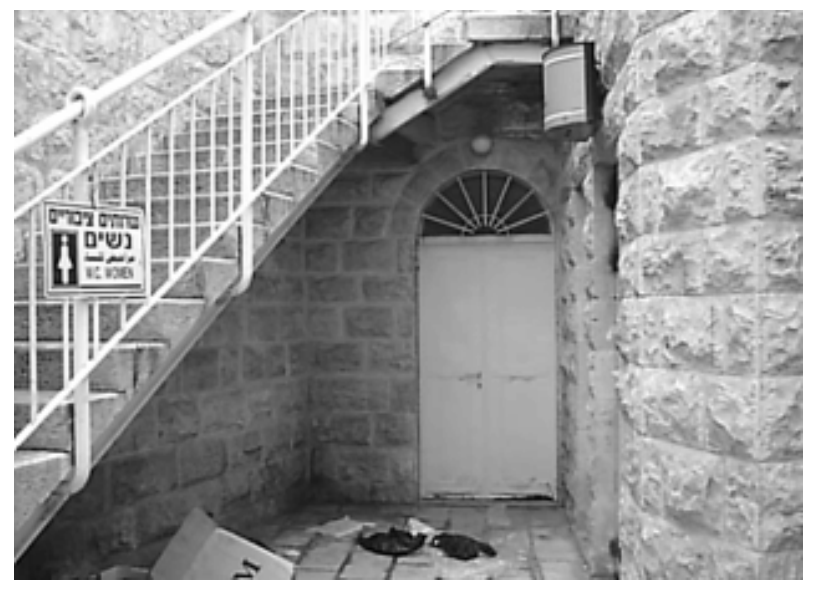

Picture No. 5: A public toilet up, a neglected store below, and a dirty floor covered with rubbish.

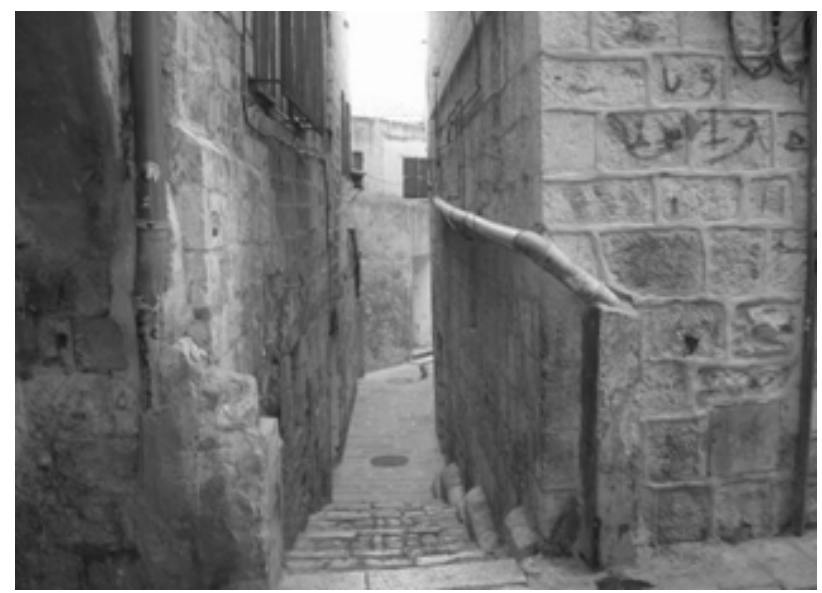

Picture No. 6: An open narrow alley way with many corners and angles

Figure 2. Typical residential courtyards and alley ways which addicts most used for the purposes of hiding oneself, hiding drugs, running away, and pretending to be innocent (Photos: The Researchers). 


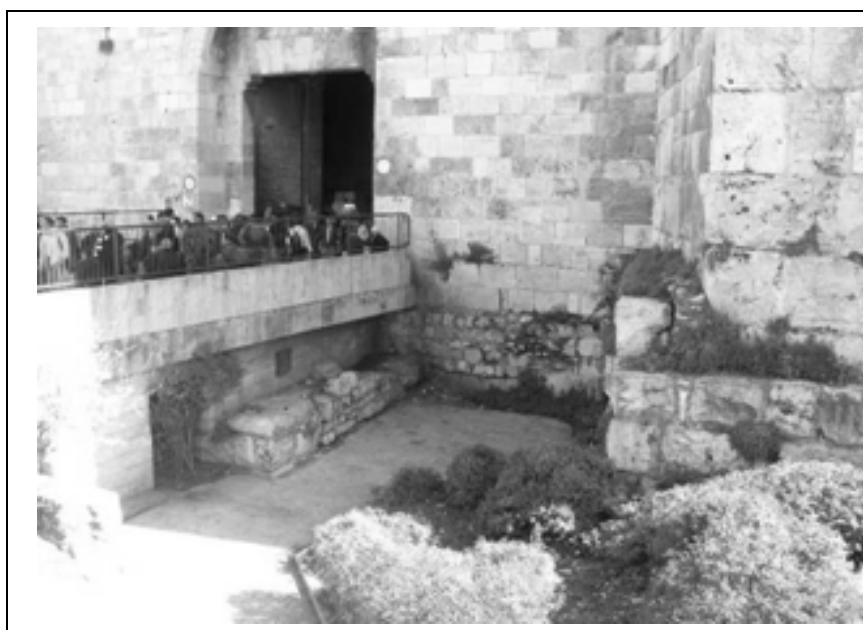

Picture No.7: A naturally created enclosure at "Bab Al-Amud" gate.

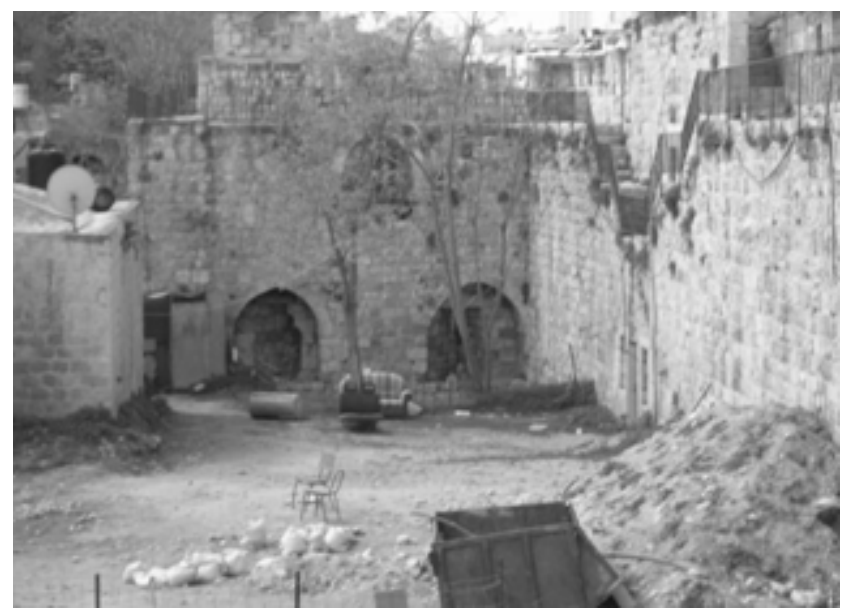

Picture No.8: A neglected place created by the city's walls near "Burj Al-Laq laq".

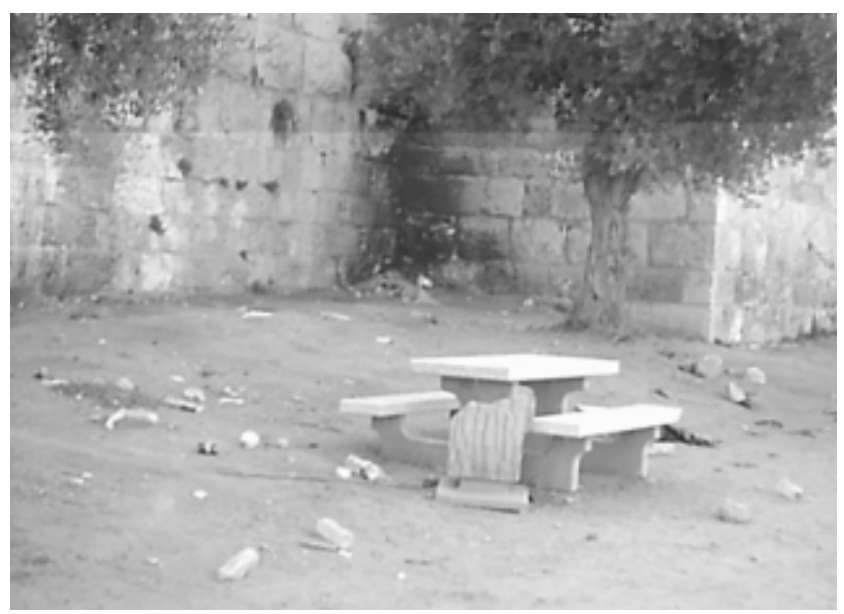

Picture No. 9: An open enclosure with trees and seats near the "Muslim" graveyard

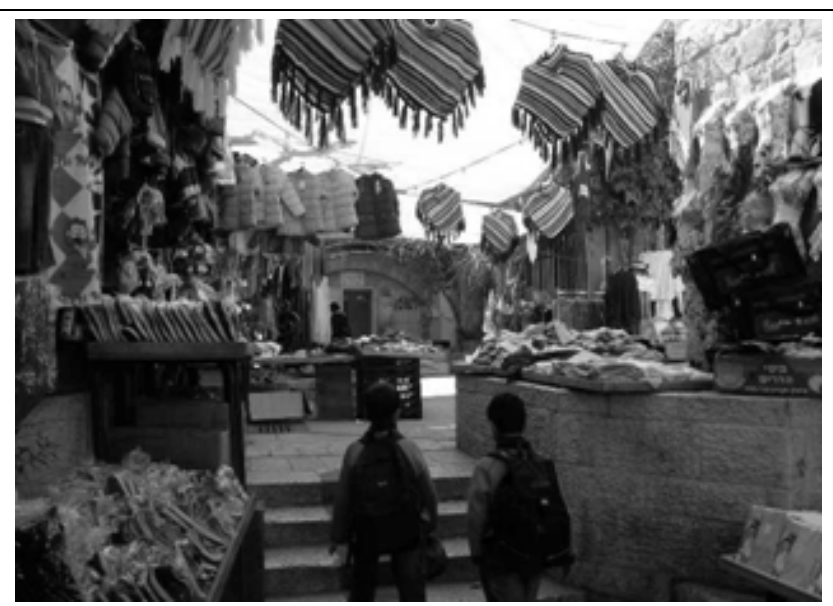

Picture No. 10: A busy market of many activities close to "Bab Al-Amud" gate.

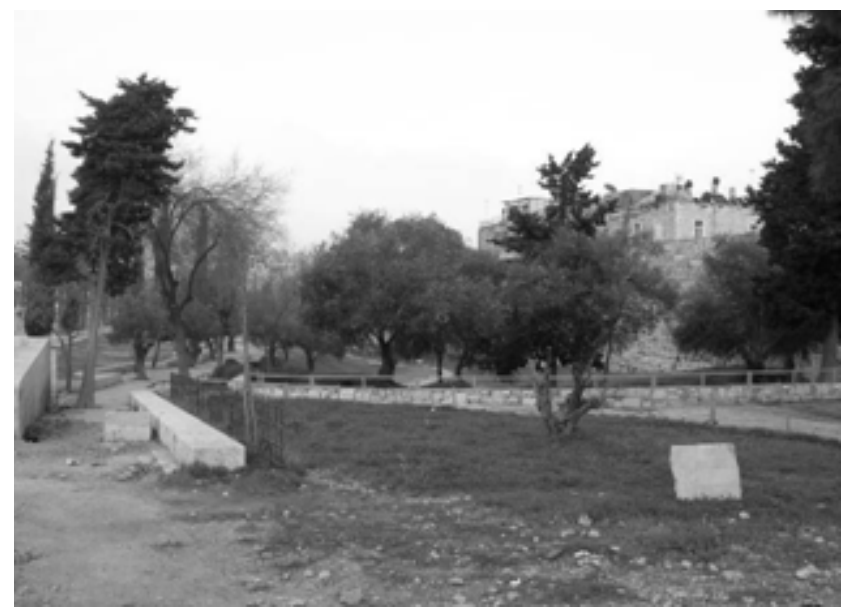

Picture No. 11: A green unpopulated place with trees and rocks close to the city's walls.

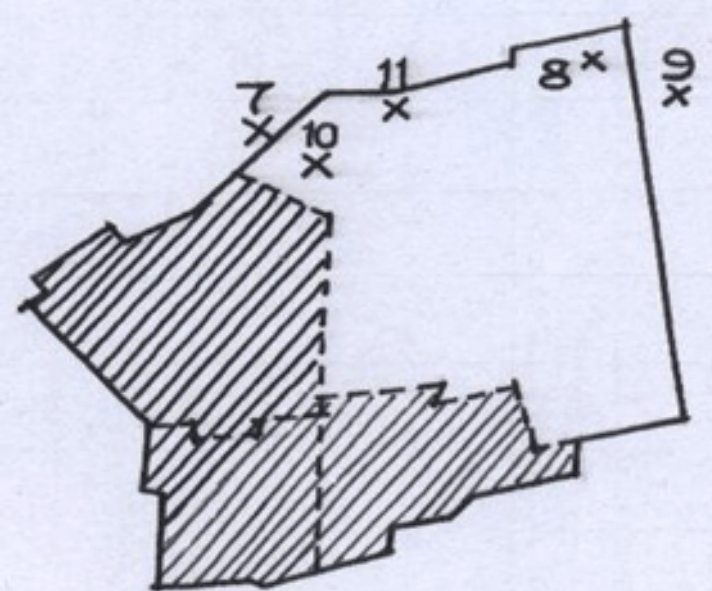

Map of the "Muslim" quarter showing the locations of the presented pictures.

Figure 3. Pictures of public places used by addicts to conveniently deal with drugs and abuse them at the "Muslim" quarter. (Photos \& Drawing: The Researchers). 


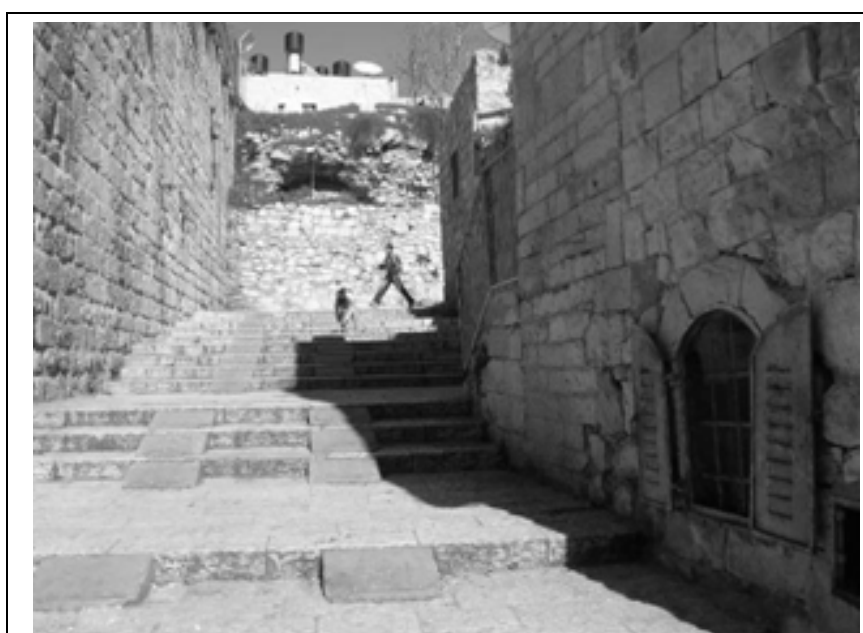

Picture No.12: An abandoned end of an alley way near the city's walls.

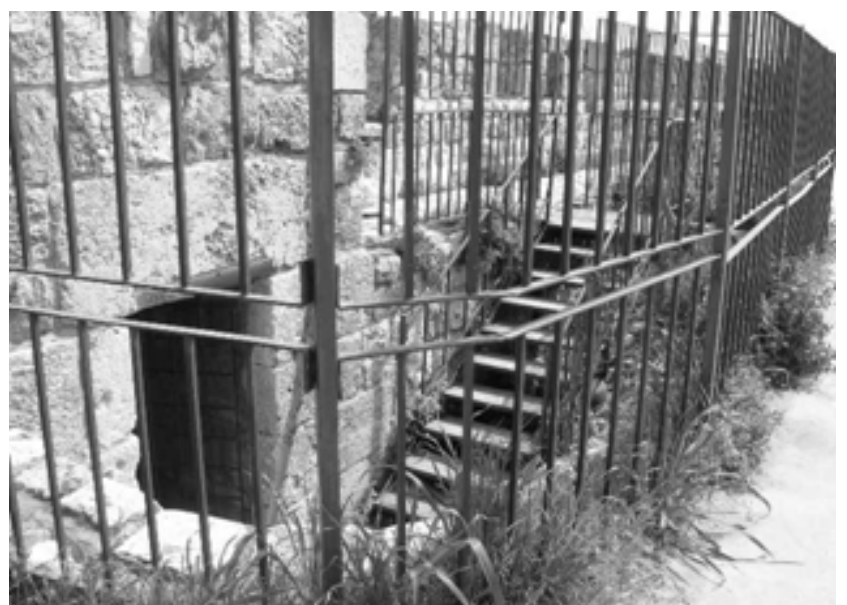

Picture No.13: An abandoned underground enclosure in "Burj Al-Laq laq" area.

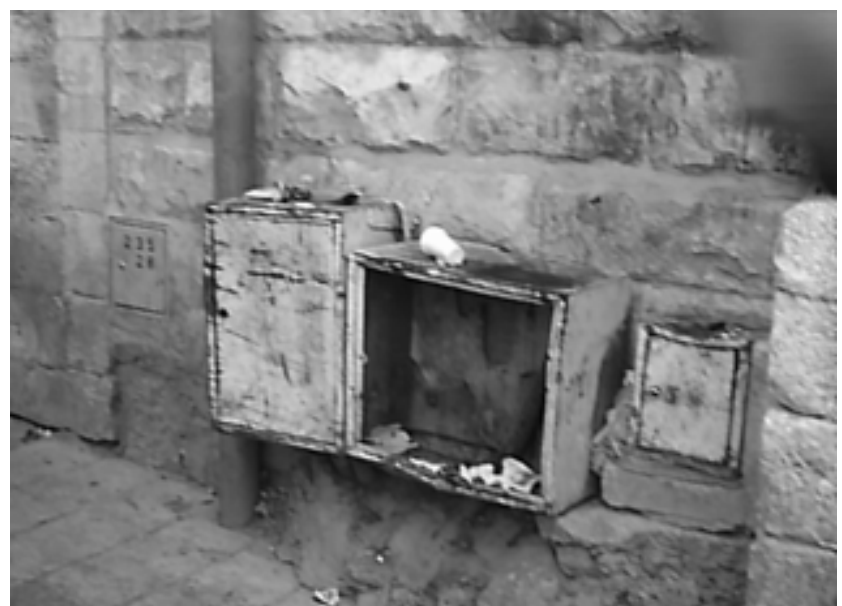

Picture No. 14: An empty box fixed on the side of the road to Bab-Hutta.

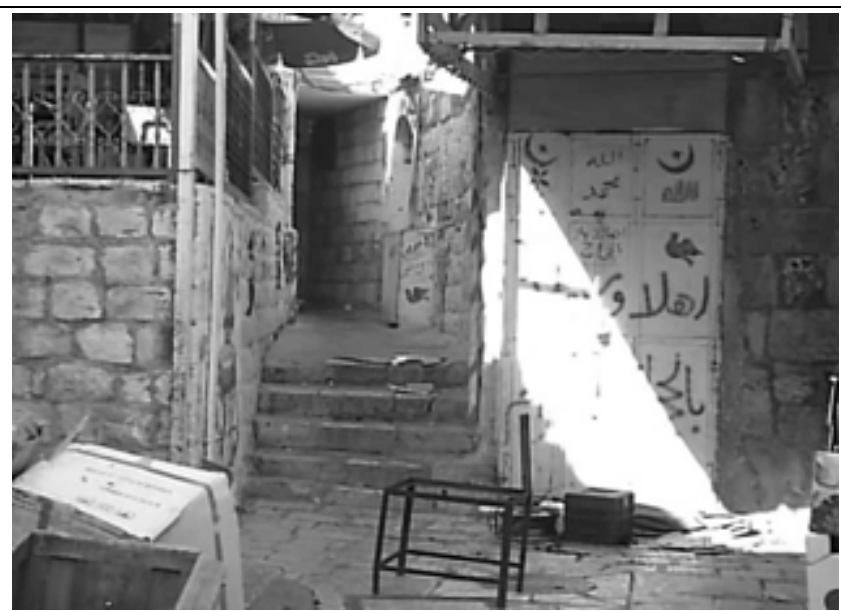

Picture No. 15: A neglected café at "Bab Al-Amud" area.

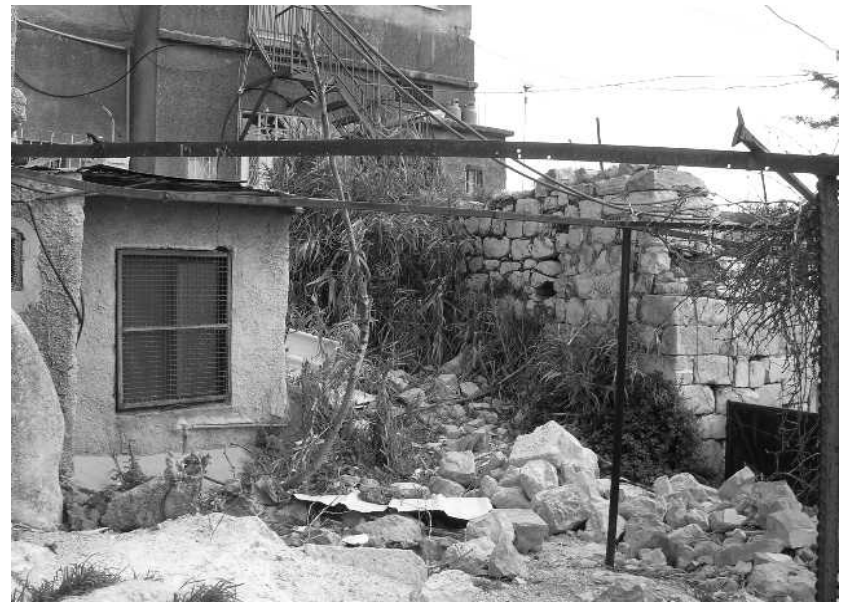

Picture No. 16: An adondaned house on the road to "Burj Al-Laq laq" area.

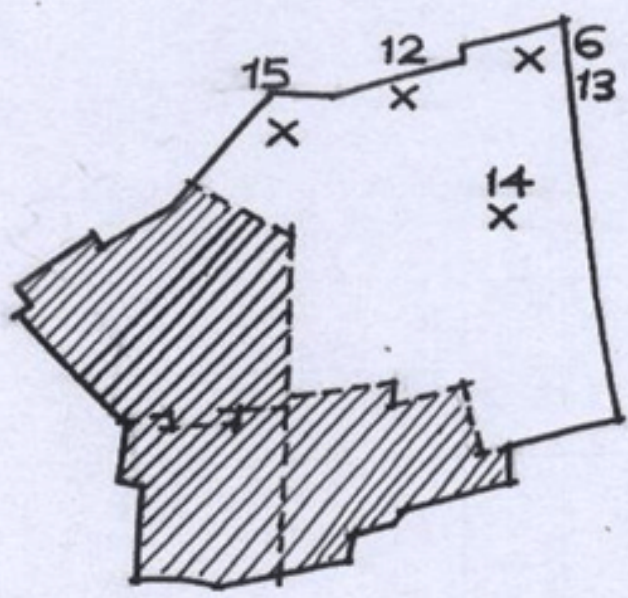

Map of the "Muslim" quarter showing the locations of the presented pictures.

Figure 4. Pictures of the typical neglected and abandoned enclosures addicts often used for hiding oneself, hiding drugs, dealing with drugs, and abusing drugs. (Photos \& Drawing: The Researchers).

\subsection{Ethical Considerations}

Before the start of each interview, the researchers explained its purpose and assured the confidentiality of information as well as the names of the participants. Also, they made it clear that all interviews would be tape-recorded and that participants were free to raise any question or discontinue the interviewing process at any point of time during the session. 


\subsection{Coding and Analysis}

Participants' spoken memories took the form of a free-flowing text that was seen as a "proxy for experience" of which codes were intended to be analyzed. Each recorded interview was first translated from Arabic to English and then made into a transcription separately filed under a coded letter (A, B, C, D, E, \& F) to correspond with the number of participants. Then, each file was carefully examined, analytic notes were made, a list of themes was concluded, and whole text was divided into meaningful themes or categories under which the collected narratives fit. The arrived-at categories and subcategories were organized according to shared patterns which related to either the "want-to-prevent" events, type, or the "want-to-produce" events [5, p. 58-86]. This method of analysis was based on the methods that have been generally used in qualitative research in different fields.

\section{Results}

Two nodes emerged from the grouping of the shared patterns with their categories and subcategories: The "Want-To-Prevent" events' node and the "Want-To-Produce" events' node. Patterns represented the common events, categories reflected the types of action needed to accomplish the underlined events, and subcategories referred to the concluded notes about how the identified places of occurrence, through their properties and characteristics, facilitated the performed actions.

\subsection{The "Want-To-Prevent" Events' Node (Figure 5)}

Patterns were 2: Avoidance of being arrested by the police, and avoidance of being robbed by other addicts.

Categories were 4: Hiding oneself, hiding drugs, running away, and pretending to be innocent.

Subcategories included almost all places of the city's built environment along with their features (i.e., the city's walls, roads, residential courtyards and dwellings, busy market, abandoned enclosures, and isolated empty areas) whose properties (i.e., darkness, farness, invisibility, crowdedness, and anonymity) enabled the occurrence of the desired actions. Each category with its subcategories were derived certain narratives as shown below.

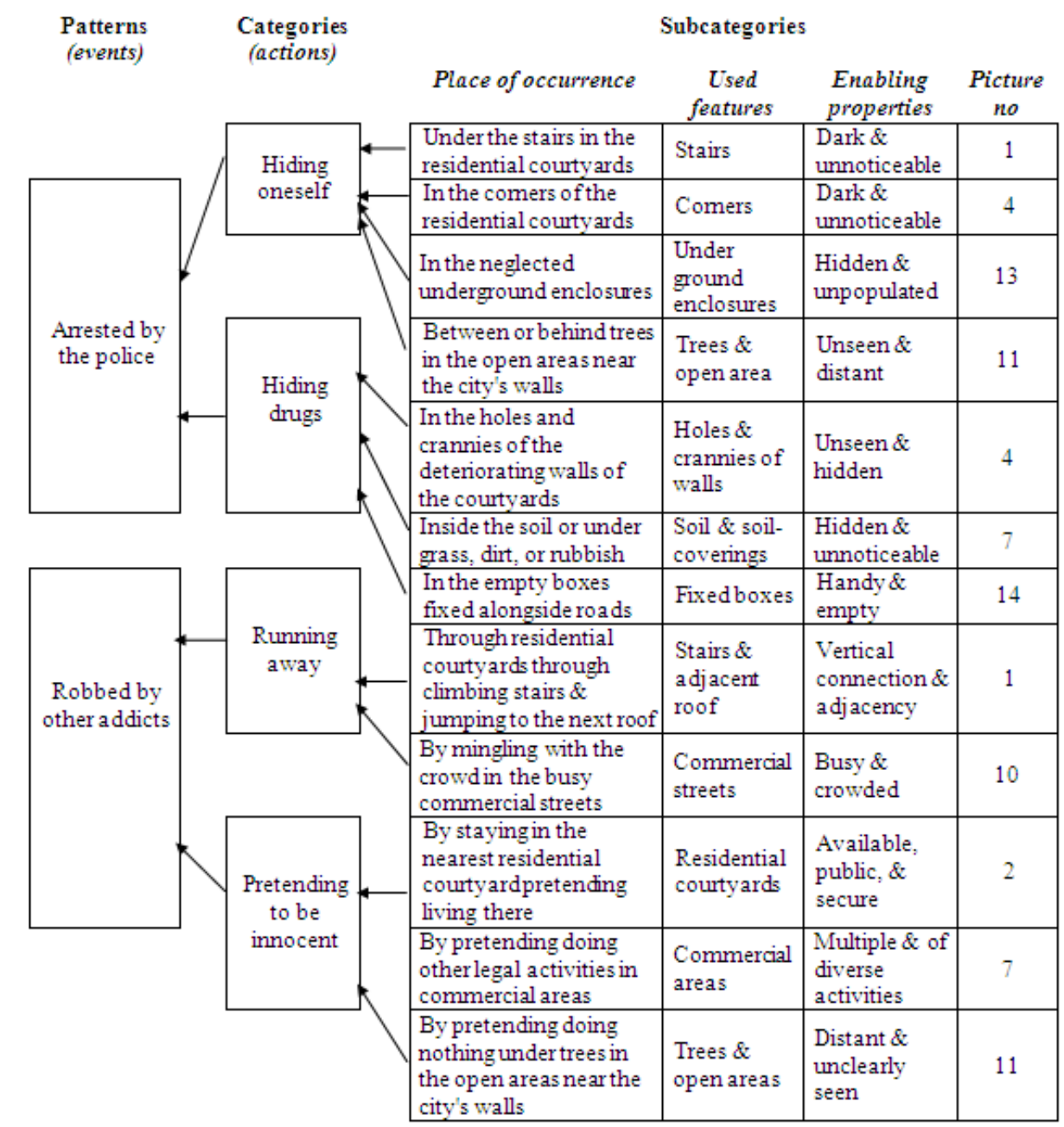

Figure 5. The hierarchical system of the "Want-To-Prevent" events' node. Subcategories point to how the physical environment of the identified places facilitated the categories of actions that are performed to sustain patterns. 
For the category of "Hiding oneself" action which occurred under stairs, in the dark corners of the residential courtyards, in the underground enclosures, and behind trees in the open areas near the city's walls:

"... This is a typical residential courtyard similar to the one of the complex where I live. When feeling in danger, I used to hide myself under these stairs or in this dark corner until it is safe. Many addicts do that often (Participant $\mathrm{C}$ on viewing picture No. 1).

"... These deteriorating steps directly accessible from street level lead down to a small underground space where I and my friends used to hide ourselves in away from the sight of the police and robbers. In those places, which are kept unlocked most of the time, you can stay as long as you need (Participant B on viewing picture No. 13).

"... I remember this place. It is good for all kinds of addiction related activities. Because of its location in the open area near the city's walls, any newcomer will easily be noticed from a far distance which gives you the chance to hide yourself behind or between these trees. (Participant $F$ on viewing picture No. 11).

For the category of "Hiding drug" action which occurred in the holes and crannies of the residential courtyards' deteriorating walls, in the soil under dirt and rubbish, in the empty metal boxes along the sides of the roads for this purpose:

"...This is a residential courtyard. Do you see its deteriorating walls? They are full of cracks and holes because of the lack of maintenance and protection. But they are very useful for hiding drugs in. The corners are also good for that purpose since they are dark and unseen (Participant E on viewing picture No. 4).

"...This is a naturally created place at Bab Al-Mud gate. We used to sit there on the rocks and lean against the walls to abuse drugs. In case of danger, we often hid drugs in the grass or in the soil under our feet. Sometimes we had to cover the buried drugs with dirt or rubbish (Participant $\mathrm{E}$ on viewing picture No. 7).

"...Oh! These boxes are very useful. Being empty and fixed at a handy level along the sides of the roads allows addicts to hide drugs inside them especially as they are left open all the time. But one needs to stay close to get drugs back when it is safe (Participant B on viewing picture No. 14).

For the category of "Running away" action which occurred when feeling in danger and consequently compelled addicts to mingle with the crowd in the busy commercial areas, disappear in the dark angled alley ways, or climb the staircase of any housing unit in order to jump to the roof of the adjacent building:

"...Do you see those steps up there? Most residential courtyards in the OCoJ have them. One can easily climb them and jump to the next building's roof taking advantage of the crowdedness of housing units. I personally did that many times. But only those who live there know how to do it (Participant A on viewing picture No. 1).

"...This is Bab Al-Amud commercial area. A well known place to all addicts, drug dealers, and tourists too. Once I was there talking to a dealer when I noticed two strangers approaching me. I immediately left the spot and mingled with the crowd until I reached the connection to a dark alley way in which I disappeared (Participant E on viewing picture No. 10).

For the category of "Pretending to be innocent" action in order to escape arresting or robbery which took place in the nearest courtyard:

"...Many times I entered courtyards similar to this one where I used to sit calmly for an hour or two pretending innocence. The police thought I was a resident of this complex and suspected nothing. We know who lives there and who does not (Participant $\mathrm{A}$ on viewing picture No. 2).

"...In this place which is close to Bab Al-Amud area, my friends and I used to sit near the wall and sell drugs. When feeling in danger, we immediately hid the drugs we possessed in the soil or behind the nearby upstanding wall and pretended to drink beer. A couple of times, I remember sitting on the drugs until it was safe (Participant E on viewing picture No. 7).

"...In similar open areas near the city's walls, we used to conveniently sit under trees and deal with drugs. The openness of those sites gives you the chance to be distant, nobody can exactly see what you are doing under those shaded areas (Participant $\mathrm{F}$ on viewing picture No. 11).

\subsection{The "Want-To-Produce" Events' Node (Figure 6)}

Patterns were 2: Dealing successfully with drugs, and conveniently abusing them.

Categories were 4: Abusing drugs unnoticeably in public places, privately in isolated unseen places, quickly in the nearest safe places, and comfortably in selected places.

Subcategories, like those of the former node, covered most parts of the city's built environment whose features' properties enabled the occurrence of addicts' desired actions (i.e., the crowdedness of the market zone, the defensibility of the courtyards, the invisibility of the underground enclosures, the emptiness of deteriorated buildings, the mystery of graveyards locations, and the far-away trees in the isolated areas near the city walls). Examples of the narratives that led to each category and subcategories of action are listed below.

For the category of "Dealing with drugs unnoticeably in public places" action which was mostly done in cafes or shops in commercial areas or in the semi-public courtyards:

"...This place used to be a famous café at Sheikh Lulu not far from Bab Al-Amud gate. The area is a center of all addiction activities and is accessible to all addicts 
from the inside as well as tourists from the outside. The area is somehow isolated with many abandoned houses that are good for drug dealing purposes especially at night when nobody is watching. Another important thing is that the police seldom come here (Participant D on viewing picture No. 15).

"...I used to sell drugs to my neighbors in this courtyard. All what I had to do was to stand at the entry point and nod. Those who wanted drugs would follow me to the inside where it was safe and unnoticed from the road outside (Participant A on viewing picture No. 2).

For the category of "Dealing privately with drugs in isolated places" action which was addicts' first choice and which mostly occurred in underground enclosures, in open areas near the city's walls, in abandoned houses, and in graveyards' locations:

"... My friends and I often went to this area near the Muslim graveyard to deal with drugs. I still remember how we were comfortable there sitting on these built-in seats under the trees. However, most of our business was done at night when nobody was looking or passing by (Participant A on viewing picture No. 9).

"...I remember this abandoned house. Here I used to regularly meet with a drug dealer because of the place's isolated location and accessibility from the main road. Here, we had all the privacy we needed to exchange money for drugs (Participant $\mathrm{C}$ on viewing picture No. 16).

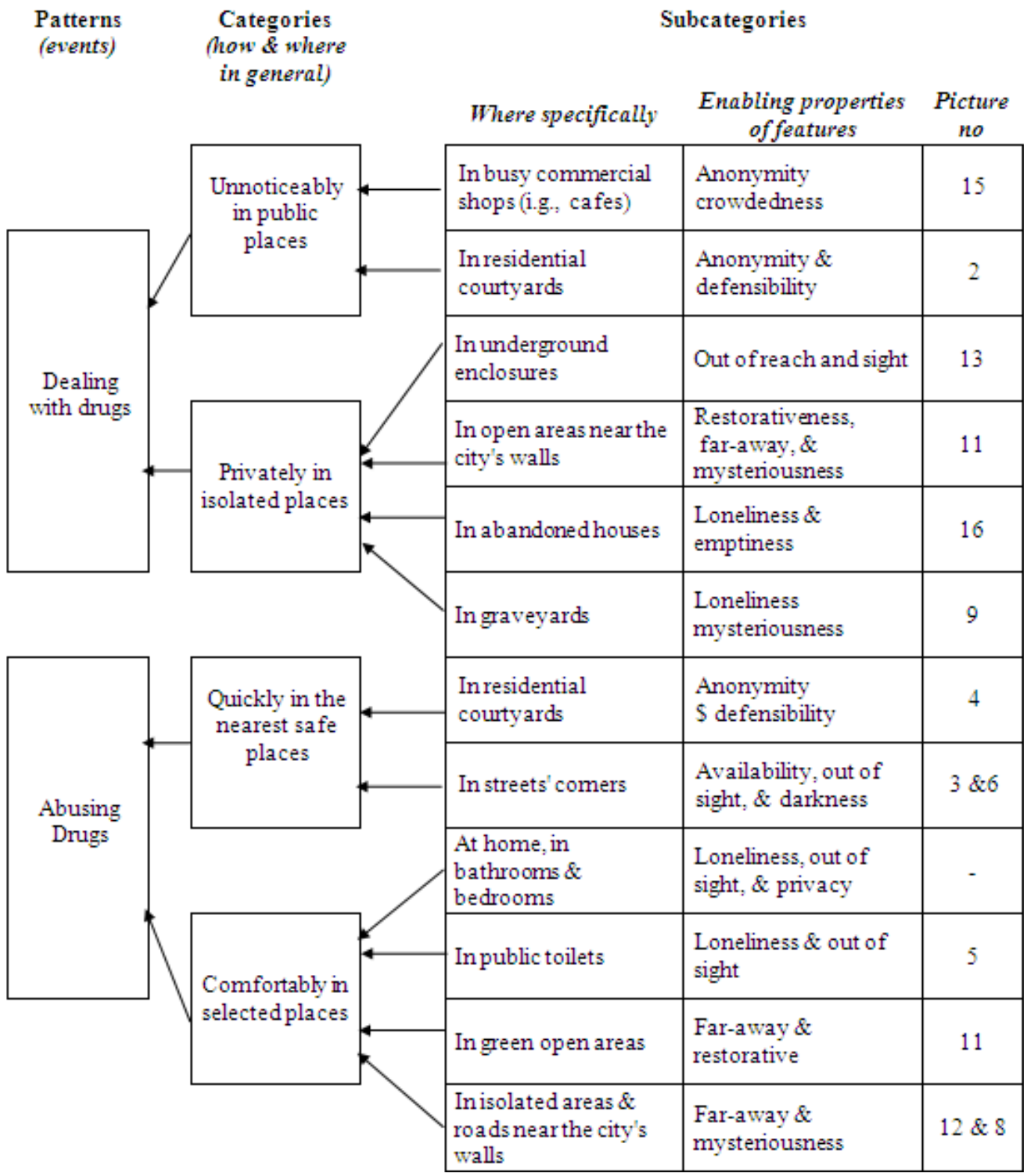

Figure 6. The hierarchical system of the "Want-To-Prevent" events' node. Subcategories facilitated the occurrence of categories, which in turn sustained patterns or common events. 
For the category of "Abusing drugs quickly in the nearest places" action which was addicts' preference in order to get drugged and avoid withdrawal sickness and which usually occurred in the nearest place such as a street corner, a residential courtyard, or a deteriorating wall:

"...Almost all addicts have experienced the situation when they needed a quick fix. To do this as fast as possible, they used to rush to the nearest road looking for a dark corner to stay in while getting high. If they didn't find such a corner, they would try to make one using any available construction sheets (Participant $\mathrm{F}$ on viewing picture No. 3).

For the category of " Abusing drugs comfortably in selected places" action which usually performed by addicts who are not very sick in public toilets, open green areas and neglected roads near the city's walls and which was found to have a positive psychological influence on addicts who needed to hang out, relax, or feel detached from the real world:

"...I love to take drugs in public toilets. There, nobody can interrupt me or share with me anything. Inside there, one sees only walls and feels as if living peacefully in a different world with no exit or access to the outside (Participant $\mathrm{C}$ on viewing picture No. 5).

$"$...Lots of drug activities take place in Sheik Lulu area which is accessible from this dead- end road. Here you can take your time while abusing drugs and thinking about these impressive walls. What do they mean to us and what do we mean to them? Addicts experience a mixture of unexplainable feelings there (Participant $\mathrm{F}$ on viewing picture No. 12).

\section{Discussion}

Results indicated how the environmental features of the Muslim quarter in OCoJ through their properties and characteristics supported actions necessary for obtaining and abusing drugs. The impressive city's walls through their deep holes and dark corners were used to hide both addicts and drugs. The underground enclosures and the abandoned houses were also used for the same purposes besides facilitating drug dealing and abuse. The narrow alley ways with their labyrinthine turns and changing levels and darkness helped addicts disappear and hide away from the sight of others. And the walled residential courtyards through their configuration and connection with the housing units they served offered the possibility of hiding, dealing secretly with drugs, running away, and pretending to be innocent. Even the green open areas adjacent to the city's surrounding walls were found useful in providing the needed relaxing atmosphere away from the inner parts of the city. Evidence on the contributing role of the environmental properties of the city to drug abuse behavior was sensed from participants' explanations about how the state of over-crowdedness enabled addicts to disappear or pretend they were living where they did not; how the darkness of many places facilitated the act of hiding oneself; and how the oldness of that part of the city and the deteriorating condition of most of its buildings made addicts feel as if detached from the real world.

A thorough reading into addicts' situated actions and activities in the Muslim quarter in OCoJ draws one's attention to three points: a) most of the performed events occurred in areas near the city's walls (see locations in Figures $3 \& 4$ ), b) hiding drugs and hiding oneself to avoid being arrested can serve the avoidance of being robbed too, and running away and pretending to be innocent in order to avoid being robbed can help in avoiding being arrested as well, and c) the places and features addicts used to prevent the unwanted events are more distinctive in image and specific in nature than those used for performing the wanted events.

However, all the above mentioned activities not only described how addicts used the physical environment of that part of the city, but also reflected the meanings they ascribed to it or how they perceived it [ 14, 15]. The collected narratives indicated that addicts immediately noticed what seemed important to them and quickly found strategies to use it based on its physical characteristics and their own capabilities. This conforms with the underlying notion of the functional approach to environmental perception in general, and with Gibson's [16] ecological approach in particular [14, p. 64]. Accordingly, the particular places addicts used were their echo-niches, and the functional possibilities of the significant features of those places as perceived by addicts were their affordances for that particular user group ( cf. Ref. [17], p. 64). Also, and based on Lang's ( cf. Ref [18], p. 95.) assumption, not only the potential uses of the environment were directly perceived, but their meanings or "the personal associations" called up by that environment as well. Here, those meanings can be summarized as "more opportunities to survive an illegal act" which reflected the way addicts perceived their physical environment and used it. Therefore, Gibson's ecological theory of visual perception provides a framework for critically understanding the phenomenon of drug abuse behavior in that part of the city and formulates the basis for organizing what has been discovered about it.

Nevertheless, that same environment of the Muslim quarter which this study found supportive to drug abuse actions can function in an opposite direction if it improves its image and acquires new meanings capable of elevating addicts' psychological state and minimizing their compulsive attitudes and behaviors.

Concrete ideas for implementing that wishful change include the creation of public playgrounds and parks in the vacant lots near the city's walls and the modification of many of the semi-permanent features of the existing urban context (e.g., lighting, maintenance, land uses, street-fronts, amenities of public places, and the exteriors and interiors of buildings especially those of the historic or sacred value). Such alteration will enhance the quality of addicts' lives and may affect the most related situational factors (i.e., the social, 
the economic, and the cultural) whose impact on drug abuse behavior cannot be neglected or denied. Results of dealing with the problem in this way will most probably reflect a decline in addiction rate, but not a happy ending unless addicts receive clinical treatment and take part in encouraging activities to become normalized members of their society. Many addicts may have difficulties in coping with such plans to defeat their illness, but eventually they will learn from watching the recovered ones and listening to their stories.

However, the present study has limitations. The employed self-report methods of interviewing and storytelling are not as reliable as the method of systematic observation. The used photographs simulated certain places selected by few people which raises some doubts about their credibility. Also, participants were recovered addicts, meaning that the generated information could not be as accurate as if they were real addicts.

Relating this study to previous work in the area requires deciding whether it is of the intrinsic or the instrumental case study type. In the researchers' view, it is intrinsic and unlike other studies because of its unique context into which it provides a different insight. But looking at it as an instrumental case study taken to facilitate the understanding of the drug abuse phenomenon would make it comparable to other studies which most of them focused either on finding criteria of site selection or on defining factors associated with that kind of behavior. For instance, Rengert [19] discovered that drug addicts preferred sites near drug markets in commercial areas. Galea et al. [20] concluded that disinvestment in social resources and psychological stresses in addition to the deterioration of the external built environment were among the factors associated with drug overdose in New York City neighborhoods. And Wallace and Wallace [21] confirmed that high rates of drug abuse were found in areas of deteriorated infrastructure. Those findings are seen in line with what can be inferred from the results of this study. Nevertheless, they are not the product of similar applied methodologies or sought objectives.

\section{New Directions for Future Studies}

The investigated influence of the physical environment of the "Muslim" quarter in OCoJ on drug abuse behavior can stretch out to include the interpersonal and the socio-cultural context of that context. Analogously, it can also encompass the physical, the psychological, and the socio-cultural contexts of the individual addict as well. Moreover, there are specific situations within each of those contexts which include important aspects of both the addict and his/her environment. Wapner and Demick [22] claim that this conceptualization of increasing the contexts of the context in environment-behavior studies has the potential to systematically deal with the wide range of daily problems in that area.

Another approach can focus on the environmental features or places rich in their affordances for drug abusive behavior. For instance, one may study their compositions and properties to see how they fit addicts' structural and functional characteristics, bearing in mind that those features or places have most probably another important kind of affordances which has to do with their symbolic and aesthetic availabilities as well (cf., Ref. [18] p. 95). An alternative to this approach is to consider only one particular feature or place like the city's walls or the residential courtyards, and try to elaborate on its significance to addicts. This will certainly yield additional results that could be no less valuable and interesting.

A third direction may consider the ambient environment of the OCoJ and focus on the influence of its various aspects on addicts' perception and use of their physical environment. The prevailing state of over-crowdedness in residential areas, the deteriorating condition of the majority of buildings, and the darkness and poor ventilation in most parts of the city are all aspects of that environment worthwhile studying.

Future studies may also take a different direction by adopting a socio-ecological approach which combines environmental psychology with clinical psychology [23] for the purpose of creating therapeutic settings that would promote better health for addicts in particular and for the society at large.

\section{REFERENCES}

[1] T. Hebjouks, Forgetting: Heroin in Jerusalem, JO Magazine 29 (2006), 66-75

[2] The Islamic-Christian Front. Online available from http://www.imemc.org/article/52611

[3] Al-Huda Association for the Treatment and Rehabilitation of Addicts in Shuafat. Online available from http://www.midleeastmonitor.com

[4] S. Ramahi, The scourge of drugs in Jerusalem. Online available from

http://www.midleeastmonitor.org.uk/articles/middle-east/190 7-the-scourge-of-drugs-in-jerusalem

[5] M. Agar, Ripping and running: A formal ethnography of urban heroin addicts, Seminar Press, New York, 1973.

[6] S. Fiddle, Portrait from a shooting gallery, Harper, New York, 1967.

[7] A. Sharon, Planning Jerusalem: The Old City and its environs, Keter, Jerusalem, 1973.

[8] Welfare Association Annual Report 2004. Online available from http://en.welfareassociation.org

[9] A. Sharon, Jerusalem The Old City: The urban fabric and geopolitical implications (ed.), Alternative Business Solutions, Ramalla, 2009.

[10] S. Touqan, R. Khamaisi, Jerusalem: Heritage and live, renovation plan for the Old City of Jerusalem ( in Arabic), The Arab Press, Lebanon, 2002. 
[11] S. Baqaeen, Housing Conditions in the Old City of Jerusalem: An empirical study, Habitat International, 30 (1), 78-426.

[12] R. Taylor, Crime prevention through environmental design. In R. B. Bechtel and A. Churchman (eds.), Handbook of environmental psychology, Wiley, New York, 2002, 413-426.

[13] J. M. Morse, Designing funded qualitative research. In N. Denzin and Y. S. Lincoln (eds.), Handbook of qualitative research, Thousands Oaks, CA: Sage, 1994.

[14] P. A. Bell, T. C. Greene, J. D. Fisher, A. Baum, Environmental Psychology (5 $5^{\text {th }}$ ed.), Thomson, Belmont, CA, 2001.

[15] U.Neisser, Cognition and Reality, Freeman, San Francisco, 1977.

[16] J. J. Gibson, The ecological approach to visual perception, Houghton Miffin, Boston, 1979.

[17] H. Heft, The relevance of Gibson's ecological approach to perception for environment-behavior studies. In G. T. Moore and R. W. Marans (eds.), Advances in environment, behavior, and design Vol. 4, Plenum, New York, 1997, 71-108.
[18] J. T. Lang, Creating architectural theory: The role of behavioral sciences in environmental design, Van Nostrand Reinhold, New York, 1987.

[19] G. Rengert, The geography of illegal drugs, Westview Press, Boulder, CO, 1996.

[20] S.Galea, C. Hembree, J. Ahern, M. Tracy, T. Markham Piper, T. Miller, D. Vlahov, K. J. Tardiff, The urban built environment and overdose mortality in New York city neighborhoods, Health and Place, 11, 2005,147-156.

[21] R. Wallace, D. Wallace A plague on your houses: How New York was burned down and national public health crumbled, Verso, New York, 1988.

[22] S. Wapner, J. Demick, The increasing contexts of context in the study of environment behavior relation. In R. B. Bechtel and A. Churchman (eds.), Handbook of Environmental Psychology, Wiley, New York, 2002, 3-14.

[23] K. H. Anthony, N. J. Watkins, Exploring Pathology: Relationships between Clinical and Environmental Psychology. In R. B. Bechtel and A. Churchman (eds.), Handbook of environmental psychology, Wiley, New York, 2002, 129-146. 